\title{
THE DEVELOPMENT OF FILARIA IMMITIS
}

\section{IN THE MOSQUITO.}

BY G. C. LOW, M.D.

Dr. G. C. Low showed a series of sections illustrating the development of Filaria immitis, a parasite of the dog, in the mosquito. These sections were made in the Roman Campagna in the summer of 1900 , and confirmed the work done by GrassI on the same subject just before.

The $F$. immitis is a filarial parasite of the dog, the adults of which inhabit the right ventricle of the heart, the embryos the internal and peripheral blood streams. A severe infection of adults in the heart may eventually kill the dog. The embryos may be found in the peripheral blood by day as well as by night, and they resemble somewhat closely both as regards morphology, length and breadth, the embryo of $F$. bancrofti, the commonest of the human filarial parasites. The point of distinction, however, is that they do not possess a sheath like the latter. The length of these embryo filariæ of the dog may roughly be taken as about one-ninetieth of an inch, while their breadth is somewhere about that of a red blood corpuscle. Grassi first showed that the intermediate host for the dog filaria in Italy was the Anopheles maculipennis, the embryo developing not in the thoracic muscles as in the human filaria ( $F$. bancrofti), but in the malpighian tubes. The specinens shewn were a series of sections made by Dr. Low to confirm Griassi's work. Later BANCROFT in Australia demonstrated that the F. immitis embryos of those parts could also develop in the malpighian tubes of Culex fatigans, the common brown house mosquito of Australia, and it is quite possible that other species of mosquitoes may function in other parts of the world, though so far there is no record of such having been tried. The technique of the experiments was simple. A. maculipennis mosquitoes bred from larvæ were applied in test tubes to the abdomen of a brown pointer dog which had numerous filarial embryos circulating in its peripheral blood. The mosquitoes fed readily from the test tubes even in bright sunlight, and then they were transferred to proper mosquito houses, the date of biting being carefully kept. From day to day, or every second day or so, specimens were removed, killed by dropping into alcohol, hardened, and then embedded in celloidin. Finally sections were cut. 


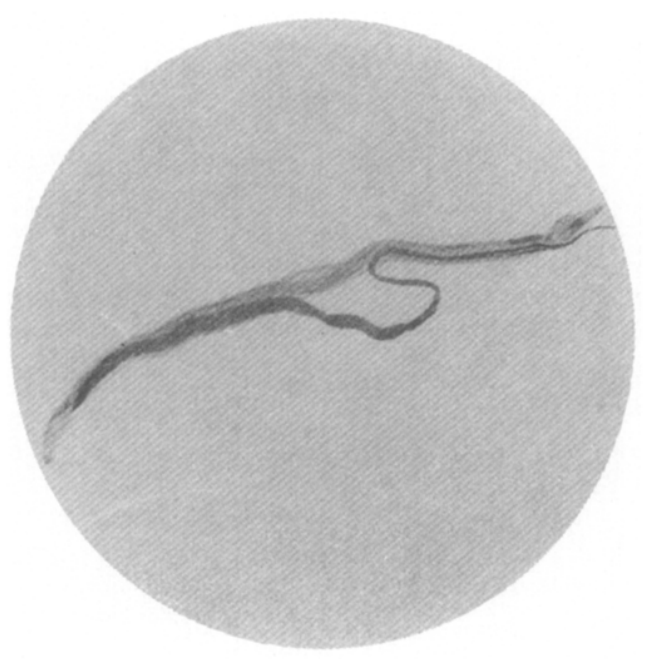

Fig. 1.

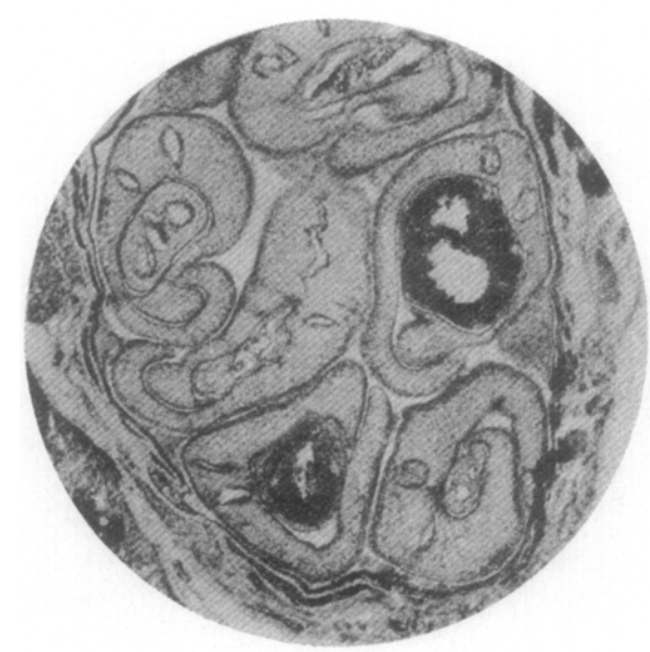

Fig. 2 .

ILLUSTRATIONS OF SPECIMENS SHEWN BY DR. T. S. KERR. 